

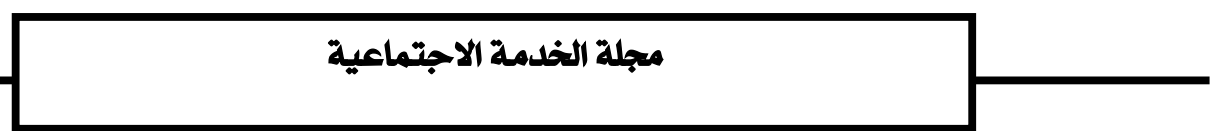


أن الاهتمام بلراسة التوافق الزواجي يُعد اتجاهاً عالمياً حديثاً، جاء مع ظهور التغيرات الاجتماعية التي ظهرت في المجتمعات المعاصرة والتي أخذت بالتزايد بأسباب التتمية والتحديث. وعلى اعتبار أن التوافق الزواجي ركيزة أساسية في نماء الأسرة واستمرارها واستقرار أفر ادها نستعرض في هذا البحث مفهوم التوافق ومفهوم والتوافق الزواجي وأهميته إلى جانب أهم العوامل المؤثرة على التوافق الزواجي والمتغيرات المؤثرة فيه، كما نتطرق إلى سوء التوافق وأسبابه، وطرق قياس التوافق الزواجي. مفهوم التو اقُق:

يعد مفهوم التوافق من أكثر المفاهيم شيوعاً في علم النفس ذلك أنه تقييم سلوك الإنسان، وعلم نفس إنما هو علم سلوك الإنسان وتواققه مع البيئة، لذلك كانت دراسة علم النفس لا تنصب على السلوك ذاته أو على التوافق نفسه بل تدور حول كيفية الوصول إلى

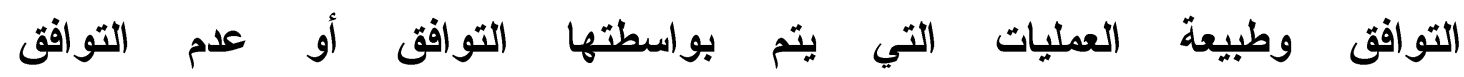
(الداهزي،ه . . ץ: צ ؟). وليس من السهل تقديم مفهوم للتوافق لما يتضمنه هذا المصطلح من معان كثيرة.

التوافق في اللغة: مأخوذ من الاتفاق والتظاهر، وهو المطابقة بين شيئين قر الكفاية، ويعرفه أبن منظور أنه وافي الثيء ما لائمه وقد وافقه موافقة واتفق معه، وتقول

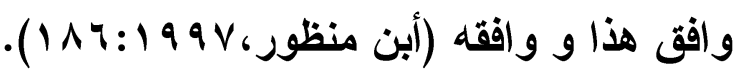

التوافق في الاصطلاح: يشير إلى العملية الايناميكية التي يحدث فيها تغيير أو تعديل في سلوك الفرد أو في أهدافه وحاجاته أو فيها جميعاً، ويصاحبها شعور بالارتياح والسرور إذا حقق الفرد ما يريد، ووصل إلى أهدافه وأثبع حاجاته ويصاحبها شعور عدم الارتياح والاستياء إذا فشل في تحقيق أهدافه ومنع من إثباع حاجاته (أبو حويج، ا ـ . ؟ : ع). ويعرفه (خليل، ، . . . PY، أنه عملية ديناميكية مستمرة يهدف بها الثخص إلى أن يغير سلوكه ليحدث علاقة أكثر توافقاً بينه وبين بيئته الطبيعية التي تمثل العالم الخارجي 
وكل ما يحيط بالفرد من أثياء حيوية وطبيعية وبين بيته الاجتماعية والثقافية التي تثمل المجتمع الأي يعيش فيه الإسان.

$$
\text { مفهوم التوافق الزواجي: }
$$

يعتبر التوافق الزواجي من أهم مظاهر الحياة الزوجية، نظراً لما له من آثار إيجابية على الحياة الزوجية، فإن كان هناك توافق زواجي بين الزوجين وجد بالتالي السكن والمودة و الرحمة و الحب، والعطف والتفاهم والآسجام و التواؤم المشترك بينهما، والعكس إن لم تكن هناك بوادر التوافق موجودة سوف يحل الزوجين التوتر في العلاقة الزوجية والصراع وغياب مظاهر الحب والرحمة. إذا كان الإسان في حاجة إلى التوافق في الحياة ومجالاتها المتعددة والمختلفة

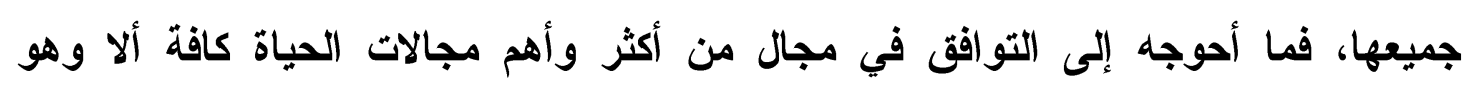
الزواج، فيجعله أكثر رضاء عن نفسه وعن أسرته، وذللك لأن التوافق في مجال الحياة

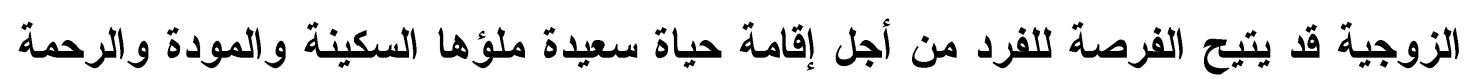

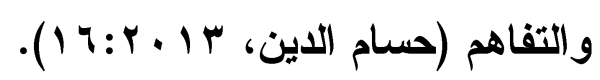

وذكرت الخولي بأن المفهوم العام للتوافق الزواجي يتضمن الاتفاق النسبي بين الزوجين على الموضوعات الحيوية المتعلقة بحياتهما المشتركة، والمشاركة في أعمال وأنثطة مشتركة وتبادل العواطف. وتنتقد الخولي مفهوم روجرز Rogers حيث قصر التواقق الزواجي على قدرة الزوجين على دوام حل الصراعات العديدة فقط وأغفل جوانب الحياة الزوجية الأخرى من تبادل عاطفي إثباع جنسي وحب متبادل ومودة ورحمة، وتحمل

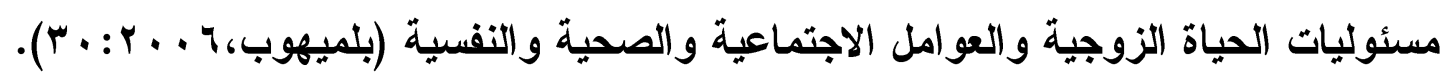

أهمية التوافق الزواجي: تتمثل أهمية التوافق الزواجي في أن ارتفاع مستواه يزيد من قرة كلا من الزوجين على تحمل الضغوط الحياتية، واجتياز الأزمات التي يواجهانها. ويجعلهما أكثر سعادة في الحياة بثكل عام وأكثر قدرة على توظيف طاقاتهما وقثراتهما للقيام بأعباء الدور، وإنجاز المهام المنوطة بهما بأكبر قلر من الكفاية. 
في حين أن انذفاض مستوى التوافق الزواجي لاى الزوجين يثير مشكلات عديدة تصل إلى حد الطلاق، فضلاً عن أنه يعد تربة مواتية الأدلاع النزاعات العنيفة بين الزوجين،

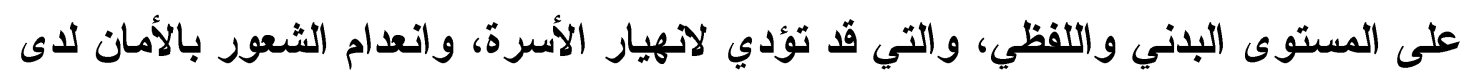

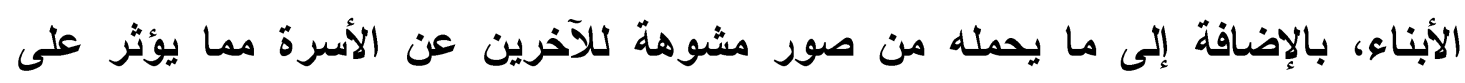

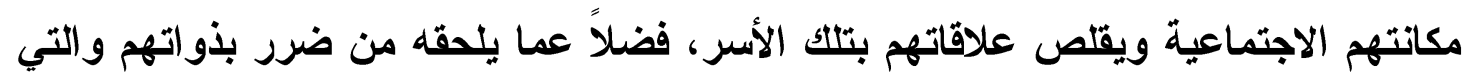

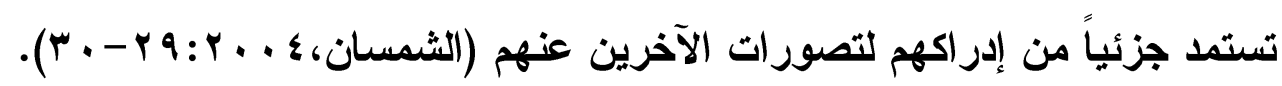
فالتوافق الزواجي هو المفهوم السيكولوجي لما يسمى بالسعادة الزوجية، فالعلاقة الزوجية إذا كاتت مشبعة لحاجات كل من الزوجين فهي إلى حد كبير ركيزة السعادة الزوجية التي تنمو في سياق تلك العلاقة، أما سوء الاثباع لتلك الحاجات لدى الطرفين أو كليهما

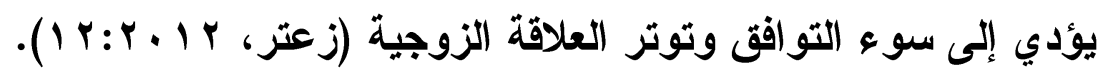

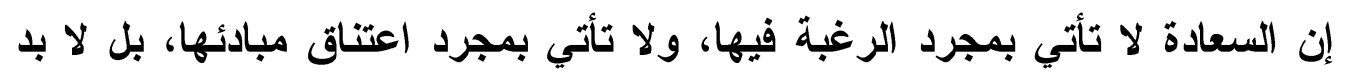
من العمل الجاد والالتزام الدائم المستمر بمبادئها، وذلكك لابد أن يتحقق في الحياة الزواجية. ولا تقطن السعادة الزوجية في البيت إلا إذا ما توافر التوافق الزواجي بين الزوجين، فتعم

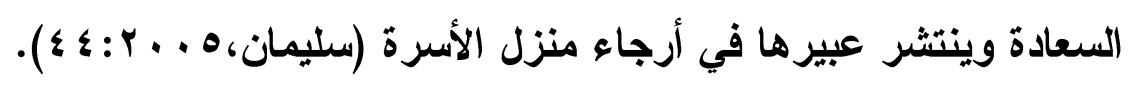
المفاهيم المرتبطة بالتو افق الزواجي: يتضمن التوافق الزواجي أربعة جوانب وهي: الرضا الزواجي، النجاح الزواجي،

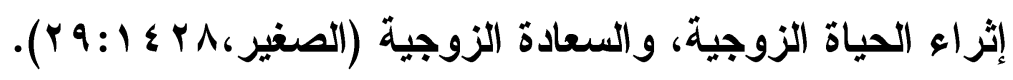

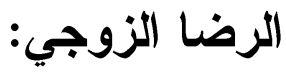
يعرف الرضا بأنه نتيجة مباشرة لدى سلوك الزوجين سلوكاً يؤدي إلى الثعور

$$
\text { بالسرور لكلا الطرفين (بلميهوب، ، 1 ـ ب:r 1 ). }
$$

وتعرف فيولا البيلاوي الرضا الزواجي، بأنه محصلة المشاعر، والاتجاهات، و السلوك التي تحدًد توجهات الزوجين في العلاقة الزوجية، ومدى إثباعهما لحاجاتهما وتحقيقهما لأهدافهما من الزواج، وذلك على نحو يستخلص من الزوجين شعوراً بالسرور والارتياح، وتنشأ عنه حالة إيجابية مصاحبة لحسن توظيف إمكانياتهما

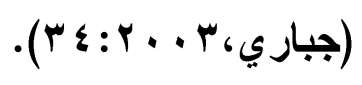




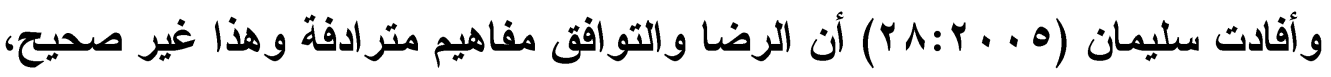
فالتوافق عام بشكل أكثر من الرضا والعلاقة بينهم علاقة العام بالخاص، فالتوافق يعني بمضمون العلاقة بين الزوجين في (جانبها السلوكي) وتفاعلاتها المتبادلة بين الزوجين في المجالات السلوكية المختلفة، واتجاه الفرد نحو العلاقة الزوجية.

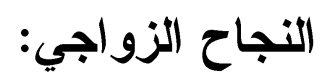
يتضمن التوافق الزواجي ويعني تحقيق أهداف الزوجين من الزواج وهي الاستمرار، و إثباع الحاجات، وتحقيق الآمال والطموحات والغايات التي تزوجا من أجلها

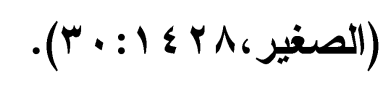

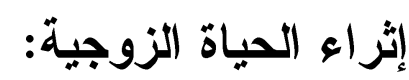
يتضمن قيام كل من الزوجين بالقيام بدوره بكفاءة تجاه الأخر، كما يرتبط بدرجة

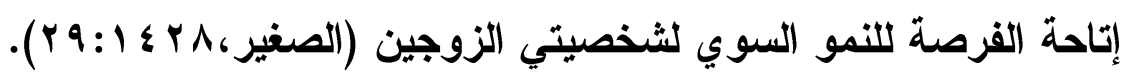

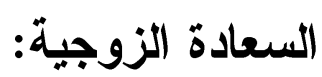
تكون السعادة الزوجية نتيجة لجه متواصل وواع من الزوجين للوصول إلى ذلك،

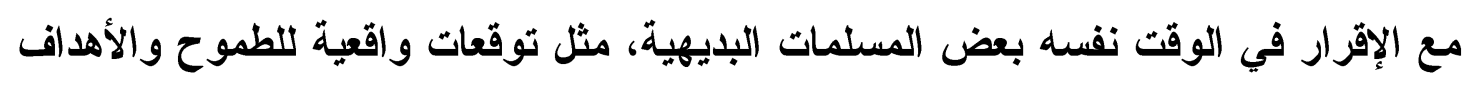

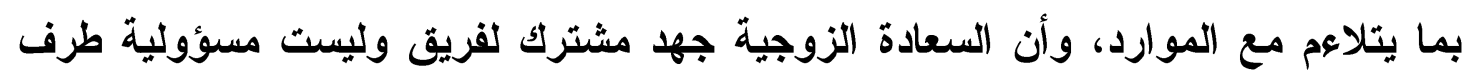
واحد، والإيمان بقدية الزواج مع قدر من المرونة، والأيمان بحق الإسان في خصوصيته

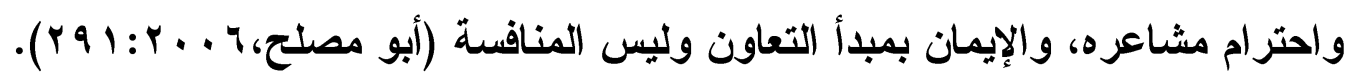
السعادة الزوجية هي نهاية المطاف الزوجي، وهي المقياس الحقيقي الدال على التوافق الزوجي، فتوافق الزوجين يكون قياسه بمدى سعادة الزوجين في الزواج، وهي الاستجابة العاطفية لدى أحد الزوجين، وتكون ناتجة عن الرضا وإثراء الحياة الزوجية

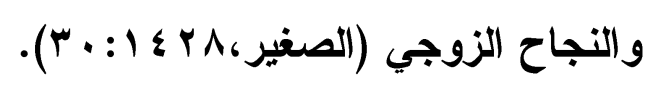

التوافق الزواجي مسألكة نسبية، تختلف من زوج لآخر بحسب نظرة كل منهما

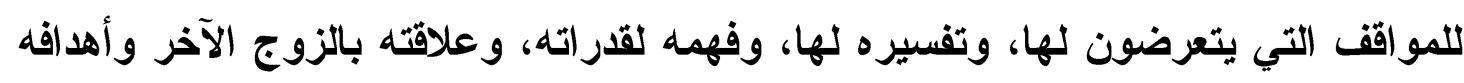
من الزواج. ويتم الحكم على التو افق أو سوء التوافق الزواجي من خلال ثلاثة زوايا: 
• زاوية الزوج: ويقصد به ما يقوم به من سلوكيات في تفاعله مع الزوجة وما يتحقق له من أهداف وما يتعرض له من صعوبات وخلافات وما يشبع له من حاجات. • زاوية الزوجة: ويقصد بها ما تقوم به من سلوكيات في تفاعلها مع زوجها وما

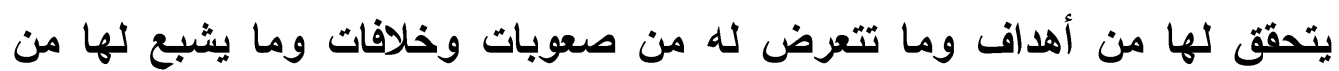

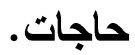
• زاوية الزواج: ويقصد بها ما يتحقق من أهدافه للزوجين والأسرة، في ضوء قيم

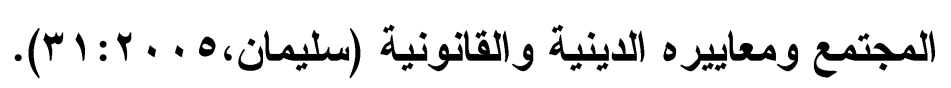

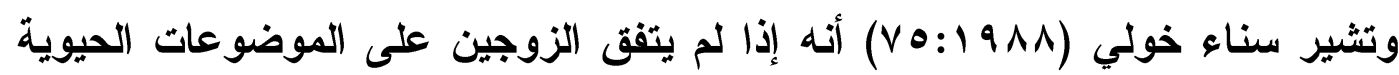
المتعلقة بحياتهما المشتركة، وإذا لم يشارك كلاهما الآخر في أعمال ونشاطات مشتركة ويتبادلان العواطف فهما زوجان يعانيان من سوء التوافق الزواجي. أهم العوامل المؤثرة على التوافق الزواجي ما يلي (مؤمن، ع . . ب . • V): ا ـ الخلفية الأسرية:

التوافق وسوء التوافق في الزواج يبدو وكأنه ميراث اجتماعي يتواجد مع الأسر جيلاً بعد جيل، ذلك أن الفرد يتوافق في الزواج أكثر إذا كان والاه قد عاش حياة زواجية موفقة، لأن علاقات الحب والدفء العاطفي التي عاثثها أثناء الطفولة والمراهقة يميل إلى تكرارها والاستمساك بها مع شريكته في الحياة الزواجية.

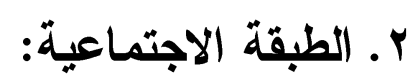

تكون الطبقة الاجتماعية الانيا أقل الطبقات استقرار في الزواج وهذا يرجع إلى تدهور المستوى الاقتصادي لهم، والزواج الذي يتكون من زوجين غير متماثلين من ناحية الثقافة أو الناحية الاجتماعية، والاقتصادية والدينية يلزمه المزيد من الجهود بقصد أحداث التكيف.

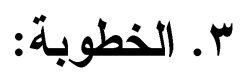

فترة الخطوبة تعتبر ذات أهمية قصوى في تمهيد الطريق لنجاح الزواج وذلك لأن هذه الفترة يزداد بها معرفة كل طرف بالطرف الآخر، وكلما كاتت أطول وبصورة معقولة وخالية من التوترات والصر اعات فإنه من المحتمل أن تستحق السعادة الزوجية. 


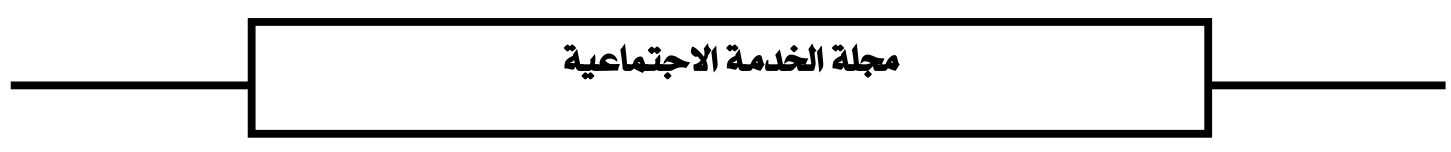

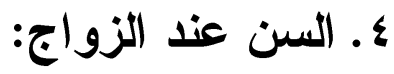

يختلف متوسط السن عند الزواج في كل مجتمع عن المجتمعات الأخرى وذلك طبقا لقدرة المجتمع على توفير فرص الحياة من عمل يرتزق منه الفرد، والمسكن الذي يأويه

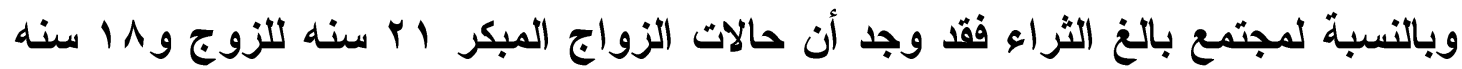
للزوجة، أباتت عن حالات الطلاق والتوتر وسوء التفاهم.

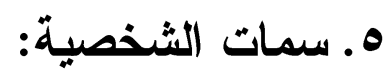

أهم الخصائص ذات التأثير الإيجابي على التوافق الزواجي هي النضج الانفعالي والقدرة على مواجهة التوترات بصوره بناءة فعالة وكذلك القدرة على نقل المشاعر والأفكار، أما الخصائص ذات التأثير السلبي بأنها تدور حول الأنانية والخداع والعناد وعدم الثعور بالمسئولية.

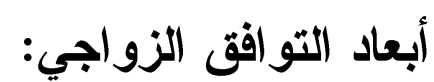

معظم الدراسات التي اهتمت بقياس التوافق الزواجي تركز بصفة أساسية على خمسة مقاييس أو أقسام: الانسام أو عدم الانسجام، والاهنمامات والأشثطة المشتركة، و إظهار العواطف والثقة المتبادلة، وعدم الإثباع، والثعور بالعزلة الثخصية والتعاسة"

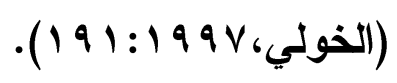

ويُعد الزوجان متوافقين زواجياً، إذا كانت سلوكيات كل منهما مقبولة من الآخر، وقام كل طرف بواجباته نحو الآخر وأثبع حاجاته، وأمتنع عن كل ما يؤذيه، أو يفسد

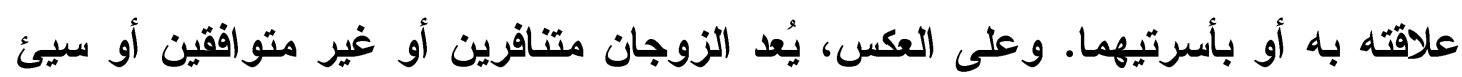
التوافق معاً، إذا كاتت سلوكيات كل منهما تؤذي الآخر، وتغضبه، أو تحرمه من إثباع حاجاته، أو لا تساعدها على تحقيق أهداف زواجهما، أو تفسد علاقتهما الزوجية

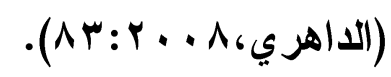




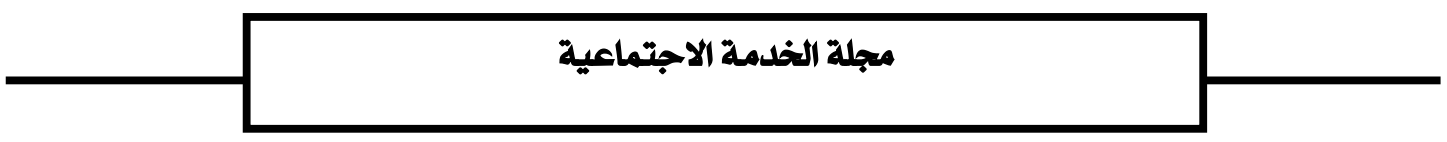

المتغيرات المؤثرة في التوافق الزواجي:

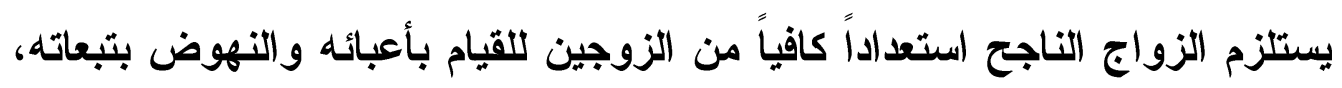
وقد تكون مؤشرات نجاح الزواج ظاهرة في قلة المشكلات النفسية والاجتماعية والمادية للأسرة، بمساعدة عوامل ظاهرة في قلة المثكلات النفسية والاجتماعية والمادية للأسرة، بمساعدة عوامل ظاهرة أو باطنة في شخصية الزوجين، أو عوامل خارجية تساهم في تحقيق هذا النجاح. ومن أبرز المتغيرات المؤثرة في التوافق الزواجي ما يلي:

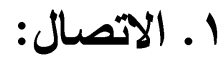

يشير مفهوم الاتصال إلى "أي فعل فردي يحدث في إطار علاقات مباشرة أو غير مباثرة مع الآخرين، ويتضمن ذلك الكلام بصفة أساسية، والإشارات البصرية و الحركية: (الإيماء، والمحاكاة، والتعبير الإيمائي)" ويمتد الاتصال بين الزوجين إلى المشاركة المتبادلة التي تكون وجدانية وفكرية واجتماعية وترويحية، ويتعدى هذا المفهوم كونه مجرد تعبير شفهي فهو يحوي تعابير بالوجه وإيماءات ونغمات صوتية. فالاتصال الجيا يعد جوهر الزواج الناجج، وهو المحرك والأداة الرئيسية

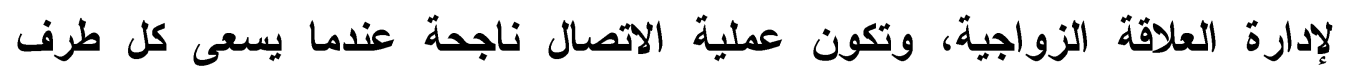
لمعرفة الكثير حول مزاج الآخر وحاجاته ورغباته، وهذا يتطلب أن يعبر كل منهما عن نفسه بتلقائية. ويثمل هذا النوع من الاتصال القدرة على التعبير عن الأفكار

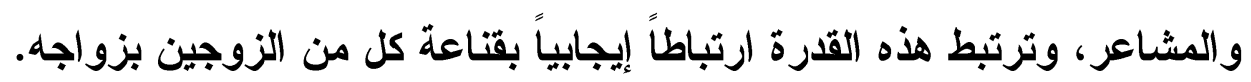
وبناء على ما سبق فإن سوء التوافق الزواجي قد يظهر نتيجة لفثل الزوجين في القدرة على التعبير الثفهي الصريح عن أفكار كل منهما للآخر، حيث يتوقع الكثير من الأزواج من أزواجهم معرفة شعورهم وأفكارهم، بالرغم من عدم

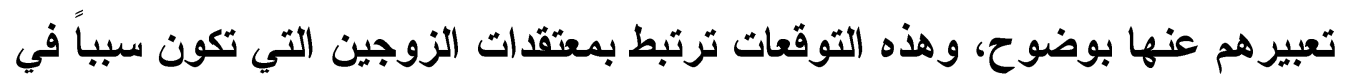
الخلاف الزواجي. ويحدث أحياناً أن يعتبر الزوج عدم استجابة زوجته أنانية منها،

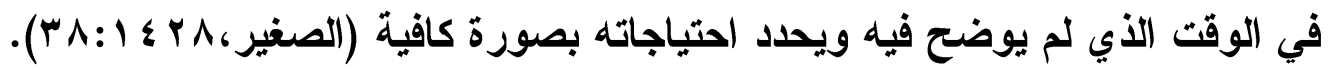




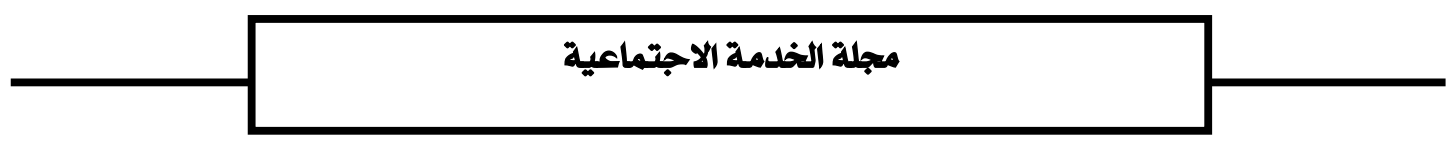

r. n أداء الادور:

يُعرف أداء الاور في علم النفس الاجتماعي بأنه: "وظيفة اجتماعية

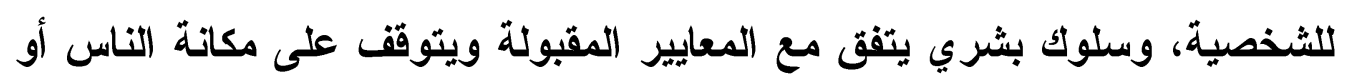
وضعهم الاجتماعي في نظام معين للعلاقات بين الأشخاص، ويشمل أداء الدور جميع

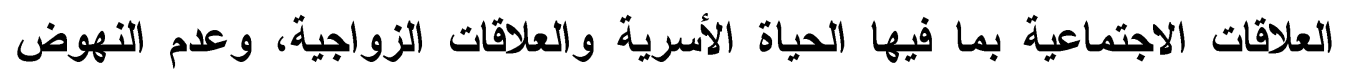

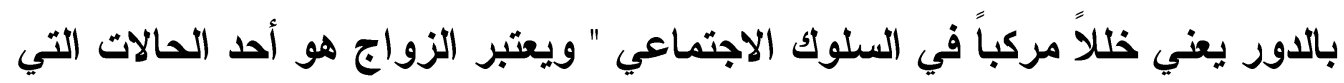

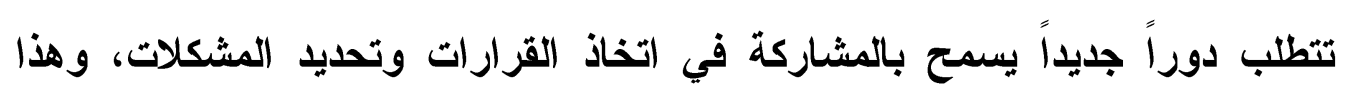
يتطلب بعض التغيير في سلوك الثخص وعاداته التي أكتسبها من قبل. وقد يبدا الصراع بين الزوجين عندما يرغب أحدهما في تغير الأدوار المتوقعة منه، فالزوجة قد تقبل بأدوارها لكن انفراد الزوج باتخاذ القرارات والسلطة لئل قد يثير لايها الرغبة في المشاركة، وقد يرفض الزوج ذلك مما يثير الصراع بينهما، وقد يرفض أحد الزوجين أو كلاهما التقسيم التقليدي للعمل بينهما، ولعل وضوح الأدوار والاتفاق في التوقعات يزيد الألفة بين الزوجين ويقلل التوتر

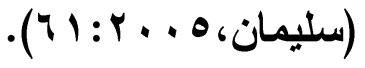

$$
\begin{aligned}
& \text { r. الجانب الجنسي: }
\end{aligned}
$$

يقتضي التوافق الجنسي فهماً ومعرفة وإدراكاً لمعنى الجنس ودوافعه وأهدافه وغايته دون زيادة أو نقصان في تقدير أهميته، وعادة ما يتطلب تحقيق التواقق تعديلاً للسلوك إذا لزم الأمر، ولابد أن يسعى كل من الزوجين للتعرف على الطريق الأي يرضي

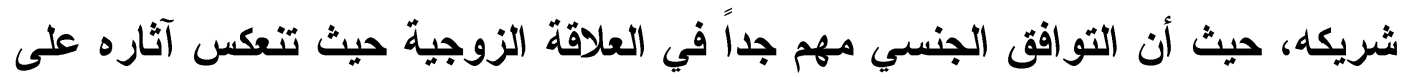
العلاقة الزوجية لذلك فإن عدم التجاوب العاطفي والجنسي يهلد العلاقة الزوجية فقد

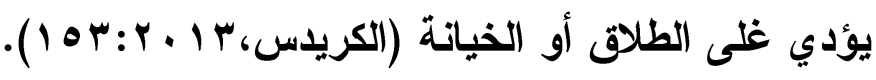

$$
\begin{aligned}
& \text { ع. الزمن الذي يقضيه الزوجان معاً: }
\end{aligned}
$$

تُعد الرفاهية الاقتصادية من أهم العوامل التي وفرت للأفراد أعمالاُ محددة وبساعات محدودة، وتلخلت مؤسسات اجتماعية للقيام ببعض أدوار الأسرة، وبناء 
على ذلك أصبح الأزواج يقضون وقتاً متزايداً معاً مقارنة بالماضي. ويُعد وجود

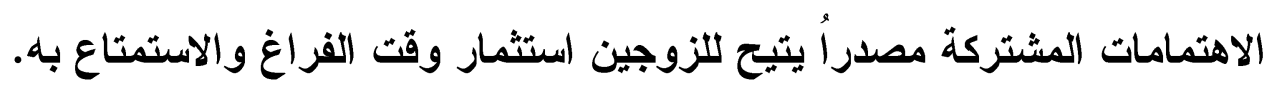
وقد بدأت الثكوى في انخفاض الزمن الذي يقضيه الزوجان معاً عند بعض حديثي الزواج، وبعد مرور 1 أثثهر من الزواج. وفي وقت لاحق تأثرت الاهتمامات

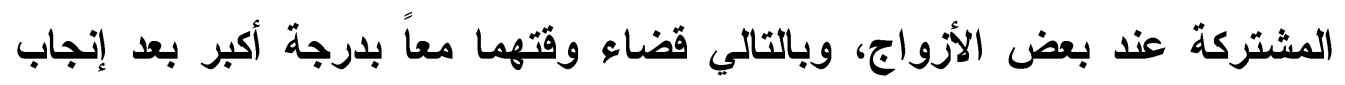
الطقل الأول وقد أجريت بعض الاراسات لمقارنة سلوكيات الأزواج السعداء

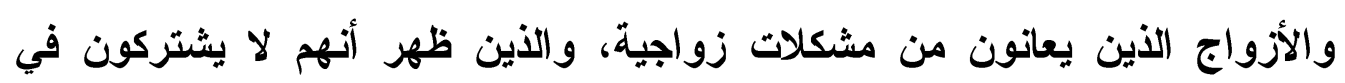

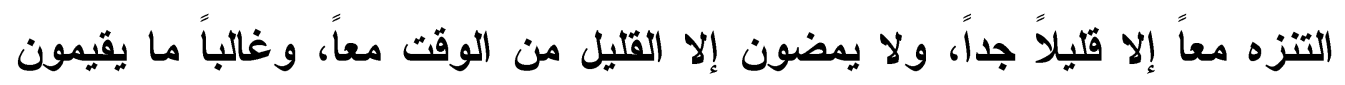

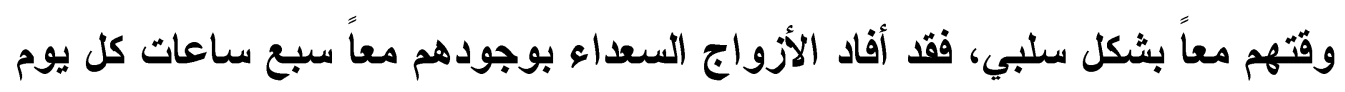

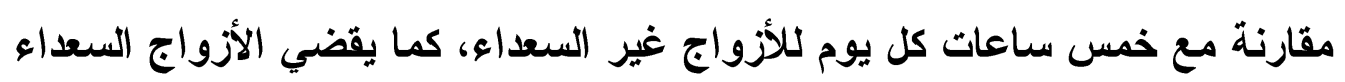
مزيداً من الوقت في الحديث عن المواضيع الثخصية، وقضاء وقت أقل في التحدث

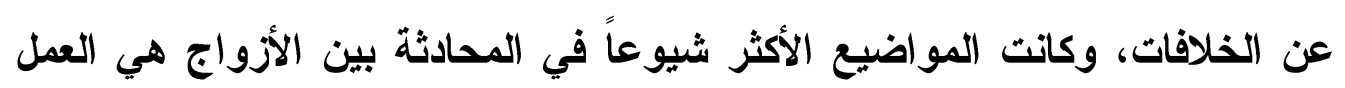

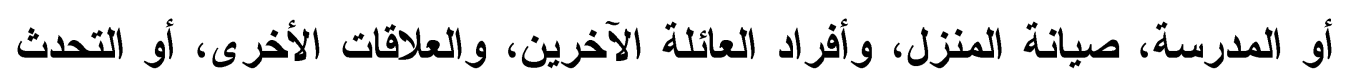
على الهاتف وعن الطعام، مع قدر ضئيل من الحديث عن العلاقة الزوجية فقط، وهذا

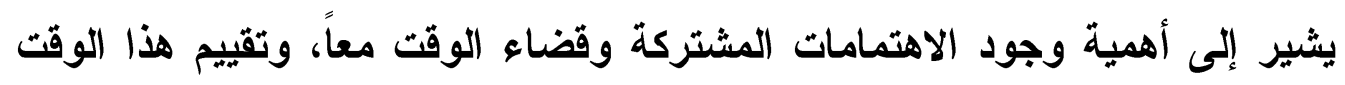

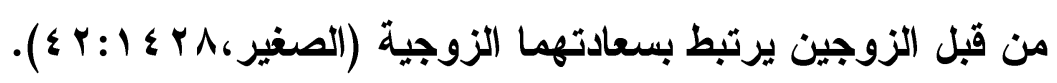

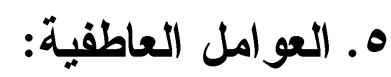

لا بد أن يكون بين الزوجين تواققاً عاطفيأ، بمعنى أن يحس كل منهما نحو الآخر بشعور الحب والمودة والتقدير والاعتبار والارتباط النفسي والعاطفي كي ترئي

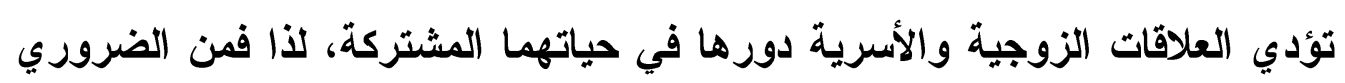
أن يكون هناك قدر ومستوى من العلاقات العاطفية المتبادلة تسمح بتوافر الراحة

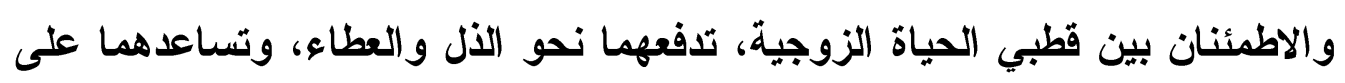
تعقيق الاستقرار الأسري. فتعاطف الزوجين يعتبر هدفاً أساسياً من أهداف الزواج، وبدون هذا التعاطف الاستيري يتحول التفاعل الزواجي إلى الكيد والثقاق والصراع، وتفقد الحياة الزوجية أهم

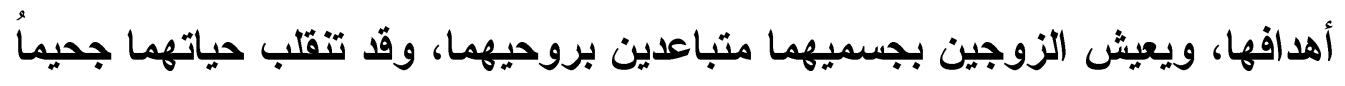


بسبب نفورهما العاطفي، والتأثير متبادل بين الحب والتعاطف، فتعاطف الزوجين

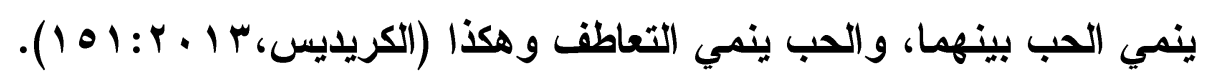

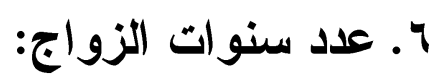

إن ثلث حالات الطلاق في الولايات المتحدة الأمريكية تحدث خلال الأربع سنوات الأولى من الزواج، وهذا يثير إلى أهمية بحث مشكلاتها. فالمراحل الأولى من الزواج

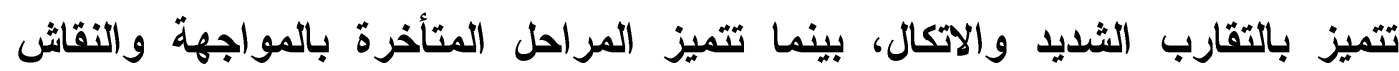

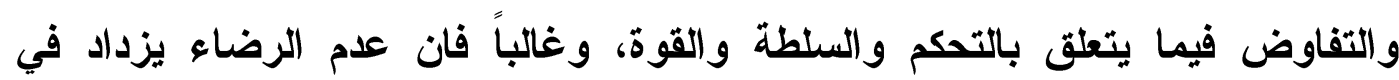
السنوات الأولى من الزواج، ومن الطبيعي أن تُدث مدة الزواج نوعاً من الروتين والفتور والنقص في الأشطة والقرارات المشتركة، وينظر الأثخاص السعداء في زواجهم بشكل أقل إعجاباً لأزواجهم بمرور الوقت. ويُعتقد أن استمرار العلاقة الزواجية ولئية

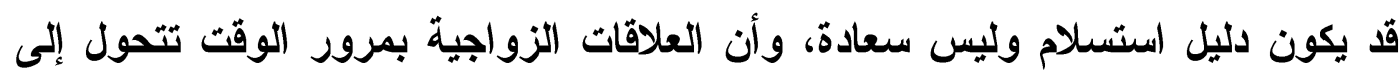

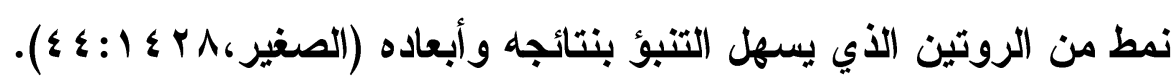
V. - العو امل الاقتصادية: الأمور الاقتصادية والمالية من الأهمية بمكان في الحياة الزوجية والأسرية، فإذا

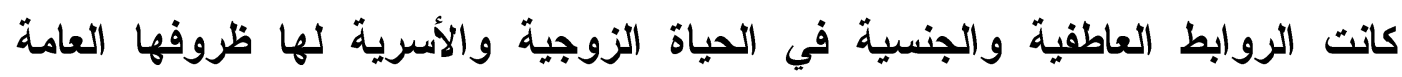
والمستمرة الواقعية والمادية بين الزوجين وأطراف الأسرة، والمطالب الاقتصادية و المادية شديدة الإحاح على الأسرة. فمن المعروف أن لكل أسرة دخلاً ولكن انخفاض المستوى الاقتصادي للأسرة قل يثير كثيراً من المشكلات الأسرية للأفراد الأين لا يستطيعون إثباع حاجاتهم اليومية

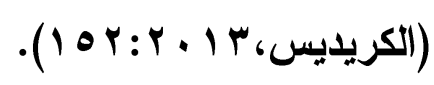

^. الاختلاف في المستوى الاجتماعي والثقافي والديني بين الزوجين: تُعد الاختلافات الأساسية بين الزوجين من أهم أسباب عدم التوافق الزواجي ومن ذلك الاختلافات الثقافية التي هي أحد هذه الاختلافات، عندما تتباين التقاليا والعادات والقيم لدى أسرة أحدها عن الآخر، وقد أثشار عدد من الاراسات إلى أن عدم الاستقرار بين الزوجين

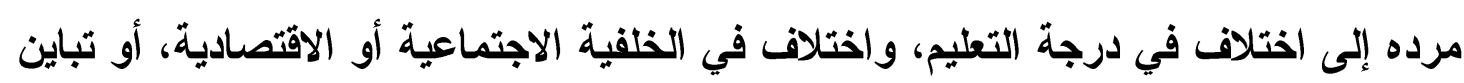


العرق أو تنافر أهداف الزوجين أو تعارضها. ولعل ما يفسر وجود الصراع بين الزوجين في حال اختلاف حصيلتهما من التعليم والمكانة الاجتماعية أنه غالباً ما يحقق التعليم قوة للمتعلم و استقلالية، وهذا يعني الاخول في مناقثات ذات محتويات هامة قد لا يستطيع أحد الزوجين مقابلتها، فكلما زادت ثقافة وتعليم أحد الزوجين عن الآخر كلما زادت الفجوة بين ما يريدان

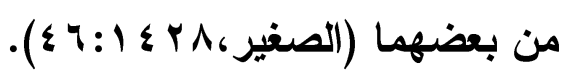

$$
\begin{aligned}
& 9 \text { ـ الخلافات البسبطة: }
\end{aligned}
$$

من المكن أن يكون للخلافات البسيطة والنادرة التي تحدث بين الأزواج أثثر سلبي على توافقهم الزواجي. وتدور هذه الخلافات حول موضوعات مثل: الالتزام بمواعيد النظافة، تناول القهوة أو الأكل بصوت عال، وترك معجون الأسنان دون غطاء، وبعثرة

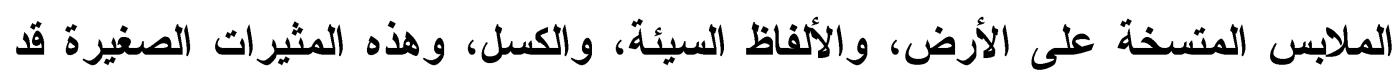

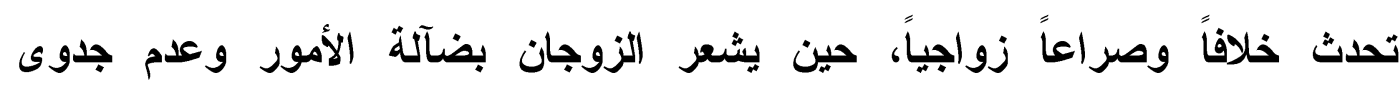
مناقثتها، ولكن لا يمر وقت حتى تثيرهما مثل هذه الخلافات البسيطة فيناقشاها بصورة غاضبة، وقد تكون ذات خطر عندما تكبت في الاذخل، وتتراكم وتتطور بمرور الوقت ويثعر احد الزوجين أن الآخر بمزايا غير عادلة، ويمارس سلطة ليست من حقه وحده

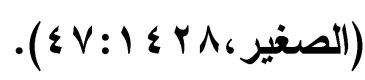

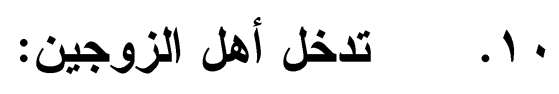

تعمل الثقافات الجماعية على إخضاع الأهداف الثخصية للأهداف الجماعية، على عكس الثقافات الفردية التي تنظر إلى مصلحة الفرد كهدف تسعى إلى تحقيقه، وأكثر تحديداً فإن الناس في المجتمعات الجماعية يحددون ويلتزمون بتوقعات المجموعات الأكثر امتداداً مثل أقاربهم وعثيرتهم والذين يرعون مصالحهم مقابل ولامهم لهم، في حين ينصب الاهتمام في المجتمعات الفردية على المصالح الذاتية

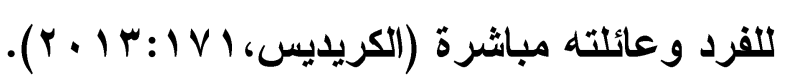

$$
\begin{aligned}
& \text { 11. التوقعات التلاو اقعية: }
\end{aligned}
$$

يُعد الاعتراف بأن حقائق الحياة الزوجية قد تختلف بصورة جوهرية عن الصورة

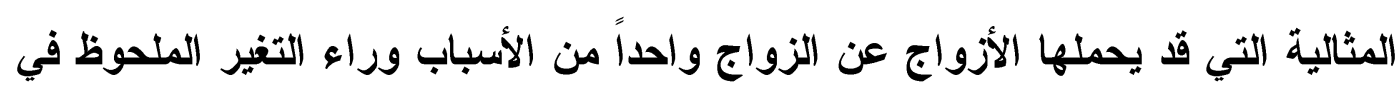


التوافق الزواجي، وفي وقت مبكر من الزواج، حيث أن الصعوبة في الاتقال إلى الحياة الزوجية هي بسبب هذه التوقعات اللاواقعية التي يقدم بها الأزواج على الحياة الزوجية هي بسبب هذه التوقعات اللاواقعية التي يقدم بها الأزواج على الحياة الزواجية، فالتوقعات غير الواقعية عن الطرف الآخر من أكثر المعززات للخلافات الزواجية. ومن المكن أن ينجح الزواج بقر أكبر إذا كان الزوجان ينظران إلى علاقتهما كعلاقة ممكنة، وأن الفوائد فيها تفوق التكاليف، ولا ينظران إليها كعلاقة متخيلة

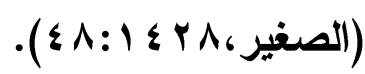
r ا ـ الثقة المتبادلة بين الزوجين: تعد الثقة بين الزوجين أهم ركائز الحياة الزوجية الناجحة. فالزواج الناجع عبارة عن شركة بين طرفين، ولكي تنجح هذه الثركة، لابد أن تكون قائمة على الثقة المتبادلة، فلا يمكن أن تكون هناكك شركة قائمة على الثكك، والخداع، و الغدر، والخيانة؛ لألك فالثقة المتبادلة بين الزوجين وإثعار كل طرف للطرف الآخر بالاحترام والأمان والثقة في قراراته وأفعاله، يعد عاملاً مهما لتحقيق أسرة مترابطة ومتوافقة

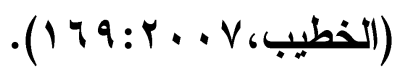

وبوجه عام يمكن حصر الأساسيات التي يقوم عليها التوافق الزواجي في مبادي

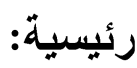

1. حجم التواصل الزواجي وأساليبه: بمعنى هل يتحثث كل من الطرفين للآخر، ويهتم بحديثه ويبدي رد فعل يعبر عن الاستجابة المطلوبة؟ r. الكفاية في القيام بالأدوار الزوجية: بمعنى هل يقوم كل من الزوجين بمسؤولياته

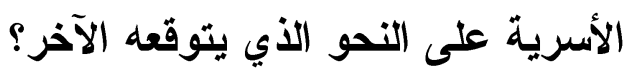
r. المساندة المتبادلة: هل يساند كل طرف الآخر ويهيئ له الظروف المناسبة لذلك؟ ع. المسايرة و التعاطف معه وتقدير موقفه وظروفه؟ ه. الإدارة: إلى أي مدى توجد الإرادة الأتية لاى الزوجة لطاعة زوجها؟ و إلى أي مدى توجد الإرادة الأتية لاى الزوج لحماية زوجته؟ آ. الموائمة: إلى أي حد يوجد لدى طرفي الزواج القدرة والإرادة والتوفيق بين

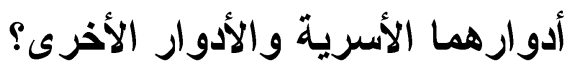


V. التلاقي: إلى أي مدى يوجد لاى طرفي الزواج وحدة الهلف وأساليب التفكير

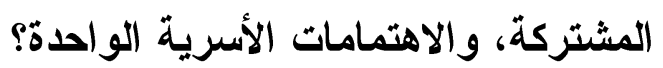

^. التكامل: إلى أي حد يمكن لكل من الزوجين أن يكمل جواتب النقص في الآخر بما

يساعد على الأداء الوظيفي الجيد للأسرة؛

9. الاكتشاف والتعزيز: إلى أي حد يوجد لاى كل من الزوجين القدرة علة معرفة المزايا

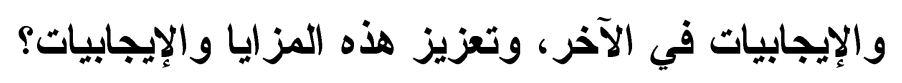

•

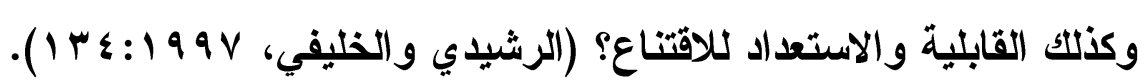

$$
\text { سوء التوافق الزواجي: }
$$

يشير سوء التوافق إلى ظهور سلوك غير مرغوب فيه من قبل الجماعة التي ينتمي

إليها الفرد، فكل من سلوك الطقل العدواني والانطو ائي يعتبر سلوكاً غير متوافق، ويعتبر هذا

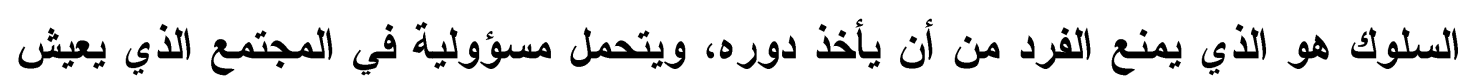

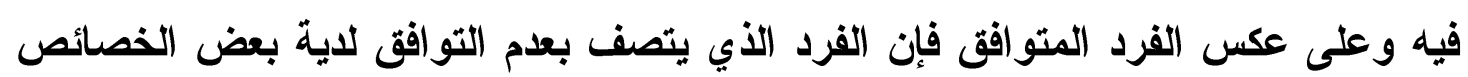
منها أن لاية درجة مرتفعة من عدم الارتياح النفسي، والثذوذ عن المعايير الاجتماعية

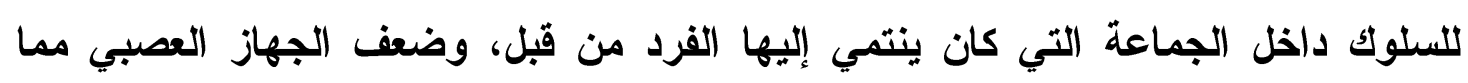
يؤدي إلى ظهور الاضطرابات النفسية والتي تؤدي إلى ضعف أو تحطم القدرة على مواجهة

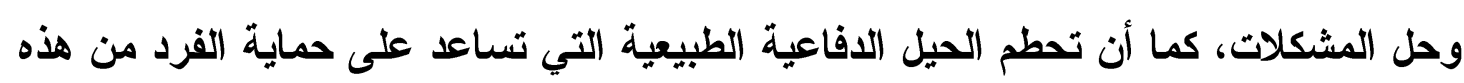
الاضطر (بات.

وعلى ضوء ذلك فإن سوء التوافق يثير إلى فثل الفرد في تحقيق التوافق السوي، ويتمثل سوء التوافق في عدم إثباع الحاجات ونقص القدرة على تحقيق مطالب الفرد بما يتلاعم مع مطالب بيئته، والثعور بالإحباط والتوتر والاضطراب حين يفشل في/ أو يعجز عن مواجهة وحل مشكلاته، وبالتالي فإنه يجنح إلى أساليب سلوكية شاذه مما يؤدي إلى لى

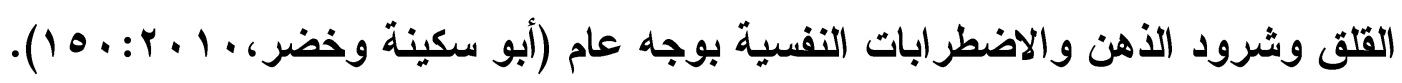
فلقد تعددت الاراسات والبحوث حول أسباب سوء التوافق الزواجي وطرحته تحت واته مسميات، منها: أسباب التفكك الأسري، أسباب الطلاق، أسباب الخلافات الزوجية، معوقات التوافق الزواجي، إلا أنها كانت تدور حول محور واحد وهو أسباب سوء التوافق الزواجي. 
وهناك عدد من العوامل تبرز سوء التوافق منها: الاختلاف بين الزوجين حول توقعات الأدوار، واختلاف قيم الزوجين، بحيث يكون لأحدها قيم متزمتة وللآخر قيم متحررة مما يولا الصراع بينهما.

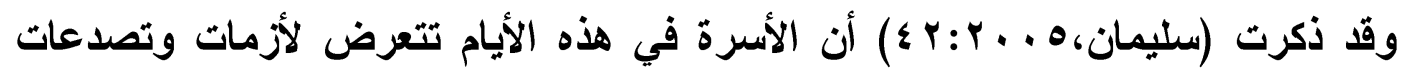
متعددة، نتيجة المتغيرات الاجتماعية والثقافية التي يعتبرها البعض شديدة الوطأة في نظام الأسرة الحديثة ويمكن أن نوجزها في خمسة أبعاد: 1. العوائق الجسمية: ونقصد بها نقص الذكاء أو ضعف القدرات العقلية والمهارات

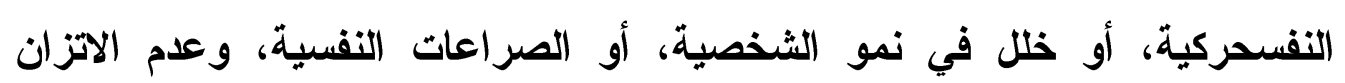
النفسي عند أحد الزوجين، وكل ذلك يمنع حدوث التوافق. r. العوائق المادية والاقتصادية: يعتبر نقص المال وعدم توافر الإمكانات المادية عائقاً

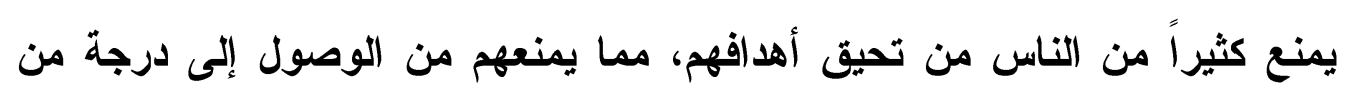

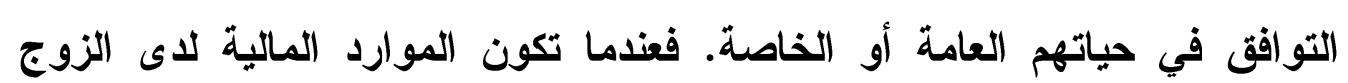
محدودة وقد يؤدي ذلك إلى عد التوافق الزواجي بينه وبين زوجته. r. العوائق الاجتماعية: ويقصد بها القيود التي يفرضها المجتمع في عاداته وتقاليده وقوانينه لضبط السلوك وتنظيمه، ومن هذه العوائق منع الوالدين أبنائهم من إثباع

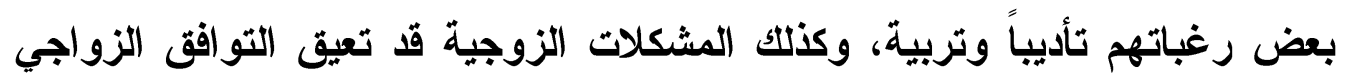
من عد تقدير كل منهما لمشاعر الآخر، وتدخل الآخرين في شئونهم الأسرية، وظهور علاقات عاطفية في حياة إحداهما. ع. العوائق الثقافية: والتي تتمثل في انتثار وسائل الإعلام الحديثة، وانخفاض الوعي الثقافي الأسري المعاش عن تصوراتهما قبل الزواج، التفاوت الثديد في مستوى ثقافة الزوجين وتعليمهما. ه. العوائق الثخصية: وتتمثل في عدم عناية الزوجة بمظهرها في المنزل، وضعف شخصية الزوج، وعقم أحدها أو المرض المزمن، والاختلاف الحاد في وجهات النظر ويُعد الطلاق أحد أهم الملامح لسوء التوافق الزواجي وهو الحل الأكثر انتثاراً لمشكلات الحياة الزوجية، ويعتبر الإسلام الطلاق أبغض الحلال عند الله لأنه ينتج عنه تفكك للأسرة 
وانهيارها وتثتت أفرادها، ولكنه يشرع عندما تكون الحياة مستحيلة بين الزوجين، والطلاق قد لا يكون واقعاً فعلياً بين الزوجين وإنما طلاقاً نفسياً غير معلن على الملأ "طلاقاً عاطقياً.

أسباب عدم التوافق الزواجي وعلاقته بتطور المشكلات الزوجية: تعد سعادة الأسرة وتماسكها هدفاً يسعى إلية الباحثون في المجالات المختلفة، ويعد التوافق الزواجي من الأمور التي تؤثر في حياة كل من الزوجين؛ مما يؤثر على شخصية أبنائهم، وعلى تكوينهم النفسي والاجتماعي؛ لذا فقد اهتم الباحثون بدراسة الأسباب الكامنة وراء عدم حدوث التوافق الزواجي أو الرضا الزواجي بين الأزواج، وهذه الأسباب عديدة

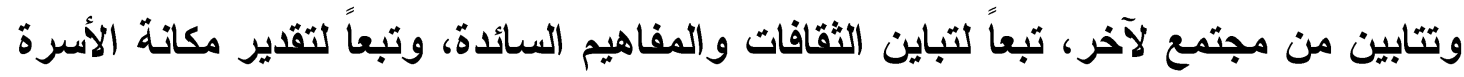

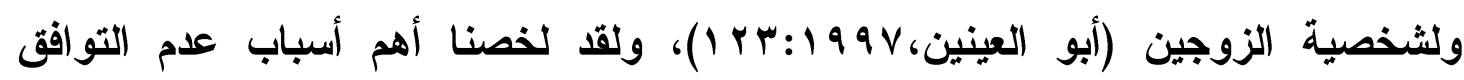
الزواجي في النقاط التالية: - النئ ا. توقعات الاور: يظهر هذا الجانب عندما لا تتفق توقعات الزوج أو الزوجة في أداء

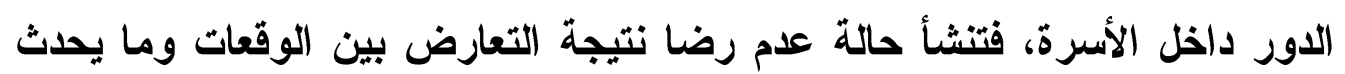
في الواقع، وربما يكون هذا التعارض مصدرا للإحباط أو الصراع في العلاقة

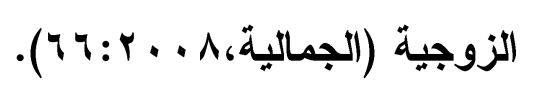

r. الوضع المالي والاقتصادي: إن أحد العوامل الأساسية المؤثرة في التوافق الزواجي،

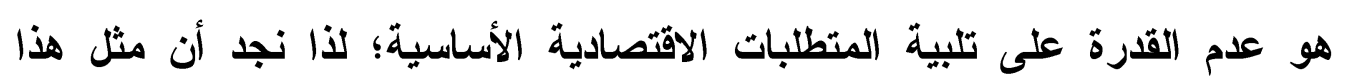

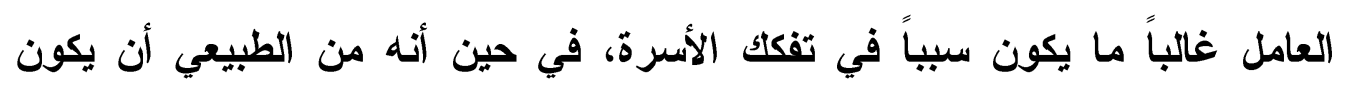

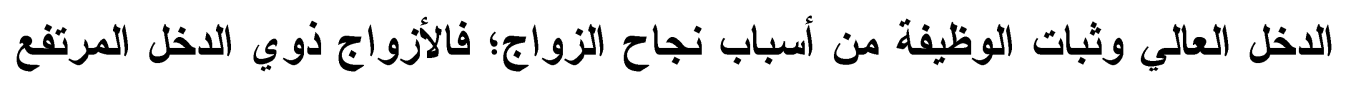
يستمر زواجهم فترة زمنية طويلة؛ ذلك لأمهم لا يواجهون مشكلات في إنفاق المال إذا كان قليلاً. r. الزواج غير الناضج (الزواج المبكر): حيث يتصف الواقعون في هذا الزواج بمحاولة

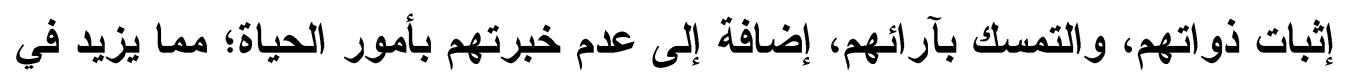

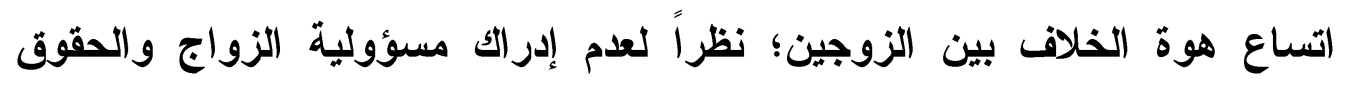

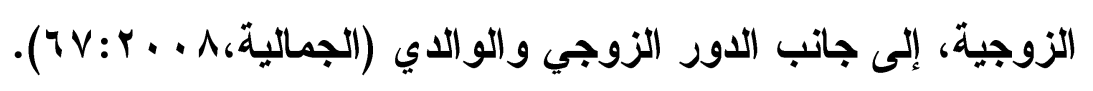


ع. الخلفية الأسرية غير السعيدة: تؤثر النثأة الفردية للطفل وتطورها في الوسط الأسري الذي صدر عنه، تأثيراً كبيراً في إمكانات تكيفه مع وسطه الاجتماعي عموماً ومع قرينته في الزواج خصوصاً. ه. الخروج بالخلافات الزوجية عن إطار العلاقة الزوجية: كالآباء والأمهات والأهل

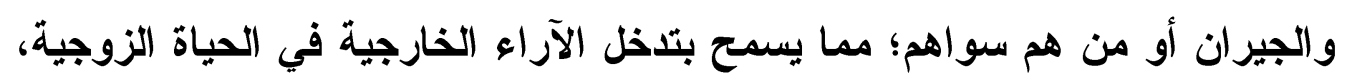
ولا يعني حدوث هذا الأمر في جميع الأحوال، فقد تكون العلاقة بين الزوجين والأهل

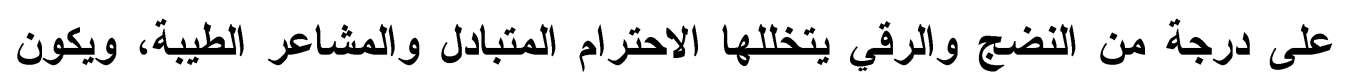
فيها الأهل عوناً لأبنائهم في تقوية روابط المحبة بين الزوجين.

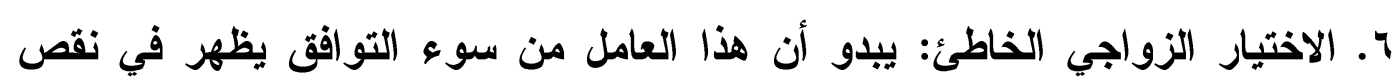

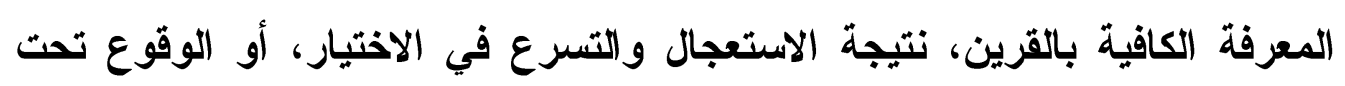

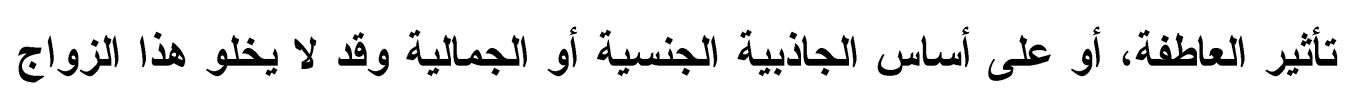

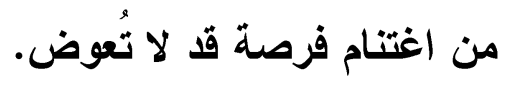

V. الجوانب الثقافية والاجتماعية: تتأثر العلاقة الزوجية بخبرات الزوجين السابقة، وبالقيم والعادات الثقافية للمجتمع الذي ترعرعا فيه، فالزواج من فرد مختلف من

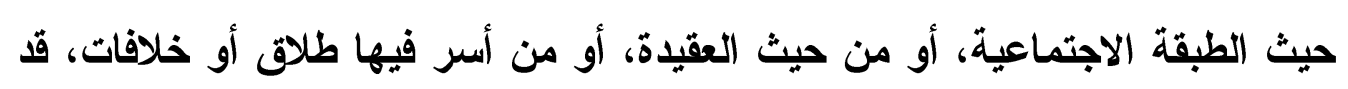
يواجه مخاطر أكبر، بحيث يمكن التنبؤ بمولا صراع بين الزوجين، إذا كان أحدهم

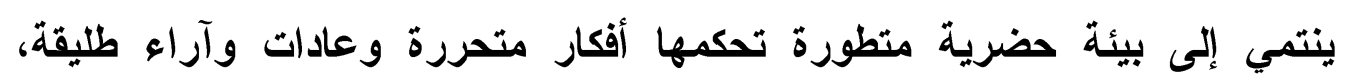
والآخر ينتمي إلى بيئة ريفية تحكمها القيم الاينية والاتجاهات المحافظة. فالتشابه لئهوره

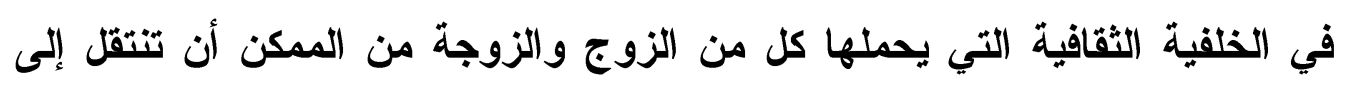

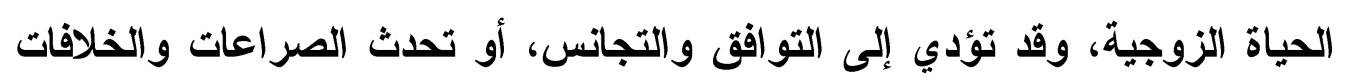

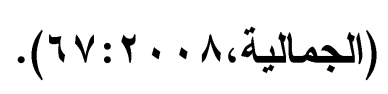

ونعتقد أن العوامل السابقة تلعب دوراً مهماً في تطور المشاكل داخل العلاقة الزوجية؛ مما يقود إلى ازدياد درجة الثعور بعدم الرضا الزوجي وعدم تحقق الاسجام، والتي بدورها تقود إلى تدهور العلاقة الزوجية، ثم إلى تدميرها بالافصال أو بالطلاق. 


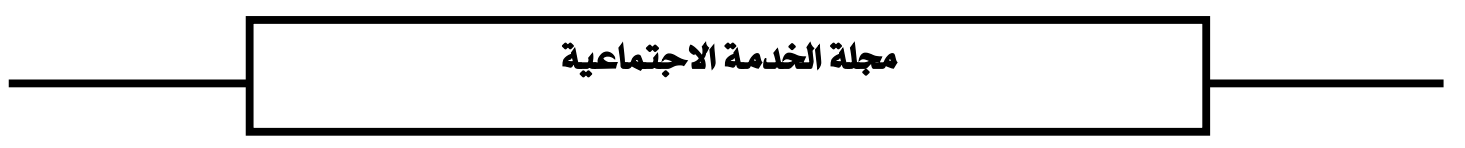

النتائج المترتبة على سوء التوافق الزواجي:

ينتج عن سوء التوافق الزواجي العديد من الاضطرابات والمشكلات في العلاقة

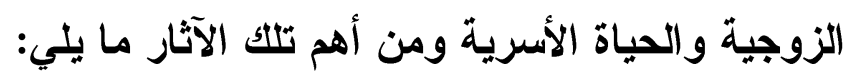

1. تعرض الزوجين لاضطرابات نفسية كالخوف والقلق والتوتر والاضطرابات التي

$$
\text { تنعكس على أدائهم اليومي على مختلف المجالات. }
$$

r. تعرض الأسرة للعديد من المشكلات التي تفرزها دائرة العياة اليومية حول أساليب معاملة الأبناء، وكيفية مواجهة مشكلاتهم خاصة في مرحلة المر اهقة. r. تتشوه صورة الأزواج غير المتوافقين، وكذلك أبنائهر في عيون الأسر المحيطة

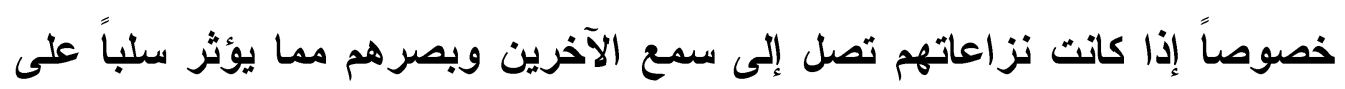
مكانتهم الاجتماعية، وتتضاعل فرص أبنائهم في عقد صداقات وزيجات متميزة. ع. ارتفاع نسبة الإصابة بالأمراض النفسية للأبناء الذين نشئوا في أوضاع عائلية

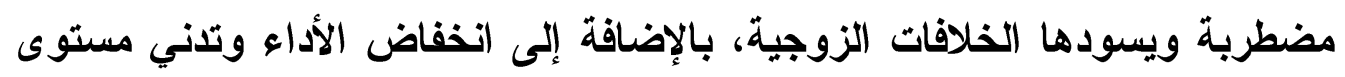

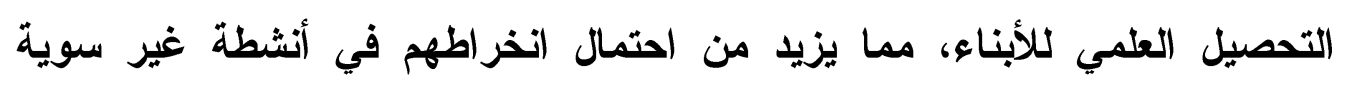
كالتعاطي أو الاتجار بالمخدرات. ه. إن سوء التوافق الزواجي إن لم يصل إلى حد الطلاق، يعد تربة مواتية لاندلاع

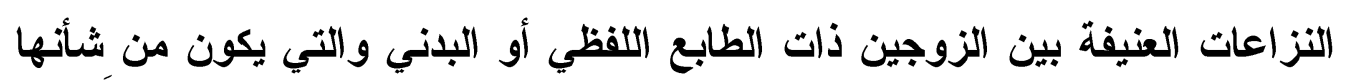

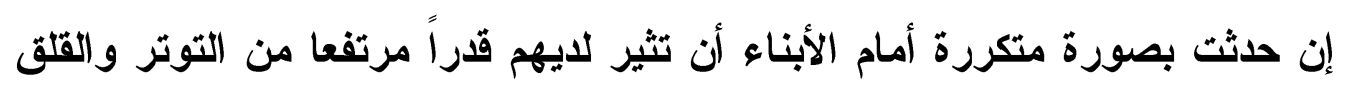

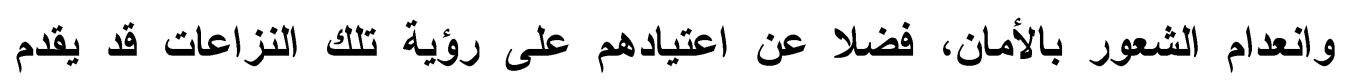

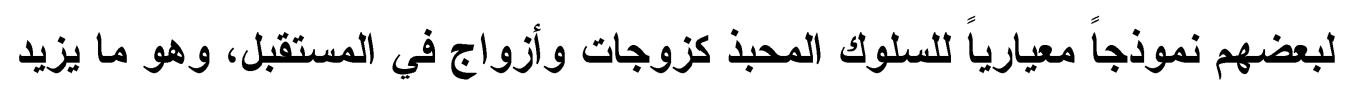
من احتمال ممارستهم للعنف فيما بعد. 4. يؤثر عدم التوافق الزواجي على إنتاجية أفراد الأسرة العاملين، مما يضر بالاقتصاد

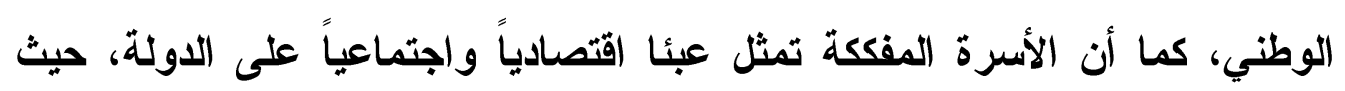

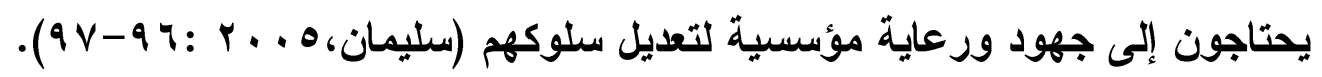




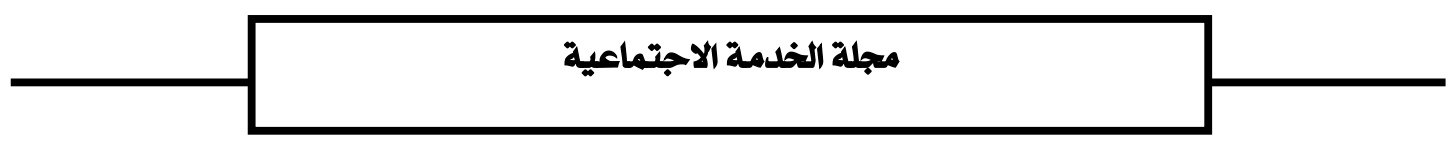

أهم الإجراءات و الوسائل المساعدة على التوافق الزواجي:

قا يعتقد البعض أن سوء التوافق الزواجي أو الزواج الفاثل ينشا عن وجود

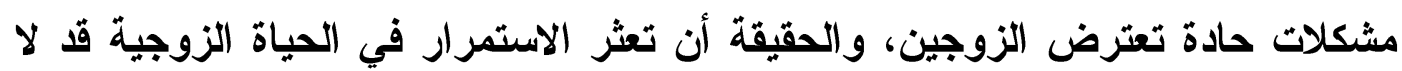
يكون بسبب وجود هذه المشكلات الحادة ولكن بسبب تجمدها وتحجر فكر كل منهما بسبيها، وقد تكون المشكلات عادية، غير أن المرونة في تفكير مل من الزوجين كفيلة في توفير قدر من التوافق الزواجي بينهما.

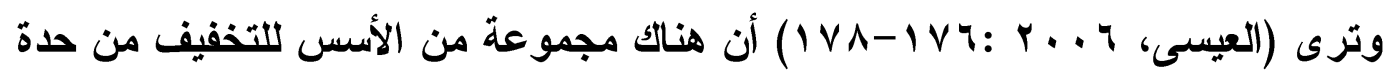
المشكلات في العلاقات الزوجية ومن أهمها:

• المرونة في التفكير والعقلانية: فهو الأساس لحل المشكلات الزواجية وقد يسهم في حل أي مشكله مهما كانت درجة حدتها أو خطورتها. أي أن على الزوجين البعد عن التجمد عند المشكلات، وعدم تصلب الرأي عند نقطة الخلاف، وأن

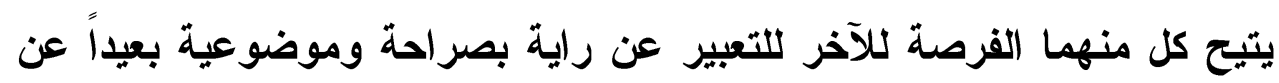
العدو انية والتجريح. • ضبط النفس والتحكم في الاففعالات: إن العصبية تبدو في سلوكيات أي من الزوجين بلا مبرر والتي تنشأ كرد فعل سريع على مواجهة المشكلات في محيط الأسرة. لذلك فإن قوة الزوجين تكون في قدرة كل منهما على التحكم في انفعالاته والسيطرة عليها، لأنه بغضبه المتكرر قد يامر العلاقة الزوجية.

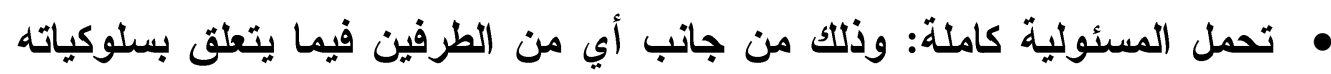
الخاطئة اتجاه الطرف الآخر، وذلك حتى لا يتمادى أي منهما صب جام غضبه

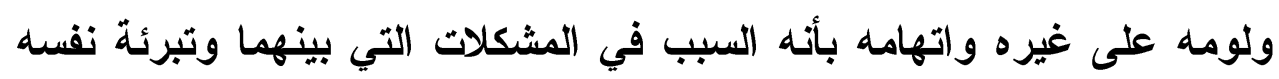
منها. إظهار الاحترام المتبادل: إن العلاقة التي تتسم بالاحترام المتبادل قد يسودها نوع من الهدوء. 
• التركيز على الموضوع الحقيقي: لأن غالبية الأزواج يجدون صعوبة في التعرف على الموضوع الحقيقي المبب للذلاف، وكلما تم تدديد الموضوع الحقيقي أصبح من السهل حل الخلافات بين الزوجين. • ع عدم التفرد في اتخاذ القرار: واتخاذها مع الطرف الآخر عند التعامل مع المشكلة حيث لابد أن يتسم المناخ بين الزوجين بالأخذ والعطاء لإعطاء الحلول والبدائل. • الميل دائما إلى التفاعل والنقاش الإيجابي وعدم اللجوء إلى العدوانية. • اللجوء إلى المرشدين والمختصين في المجال الزوجي: إذا عجز الطرفات عن حل مشكلاتهما فلابد من اللجوء إلى المرشدين والمختصين لمساعدتهم على التخلص من اضطراباتهم الاجتماعية والنفسية ومساعلتهم على تنمية أساليب التو اصل الجيد وطرق حل المشكلات. كما يرى (العيسوي،ء . .بץ:4 1) أن هناك مجموعة من الإجراءات التي تساعد الزوجين على زيادة التكيف والتوافق الزواجي بينهما ومن تلك الإجراءات: ا. ضمان أو كفالة حياة أسرية ملائمة، وتوفير ظروف تكفل النمو الافعالي الصحي، وتوفير نماذج جيدة لحياة الأسرة أو حياة عائلية أو منزلية. r. توفير الاستعداد أو الإعداد والتأهيل والتهيؤ الجيد للزواج، في ضوء فهم الواجبات و المسئوليات و والوظائف، وغير ذلك من الوقائع والظروف الأخلاقية المتصلة بالزواج و والحياة الأسرية. r. توفير الرعاية الطبية العقلية والنفسية المبكرة للزواج المريض، وقد يتضمن هذا الإجراء توفير العلاج للمشاكل الثخصية أو النفسية لأي من الطرفين أو

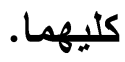
ع. مساعدة المقبلين على الزواج عن طريق تطبيق الاختبارات والمناقثات والحوار الجماعي والإرشاد لمساعدة المخطوبين والأزواج، لتوضيح وفهم دوافعهم من الزواج وفهم العوامل الرئيسية في تحقيق الزواج السعيد. 


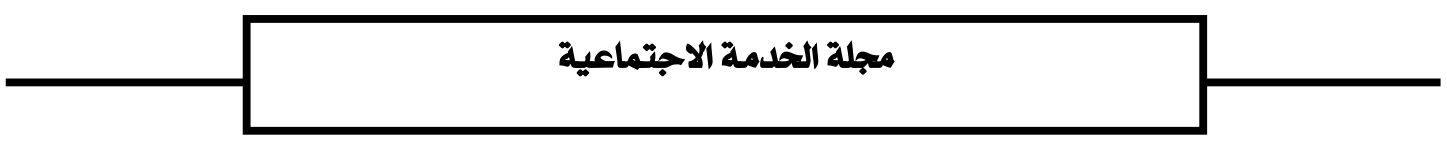

قياس التوافق الزواجي:

مما سبق عرضه يتضح أن التوافق الزواجي مفهوم متعدد المعاني، والاليل على ذللك كثرة التعريفات التي تطلق عليه. والمفهوم العام للتوافق الزواجي يتضمن التحرر النسبي من الصراع، والاتفاق النسبي بين الزوج والزوجة على الموضوعات الحيوية و المتعلقة بحياتهما المشتركة وكذلك المشاركة في أعمال وأنثطة مشتركة وتبادل العو اطف. وقد بدا قياس التوافق الزواجي بطرق متعددة في أواخر العثرينيات، ثم ظهرت بعد ذلك بعشر سنوات دراسات واسعة وشاملة اهتمت بتحديد العوامل الثخصية المرتبطة بالتوافق الزواجي، وتبين أن معظم هذه الاراسات تركز بصفة أولية على خمسة مقاييس:

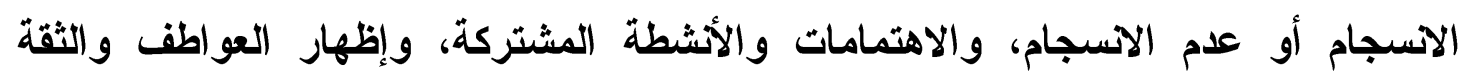

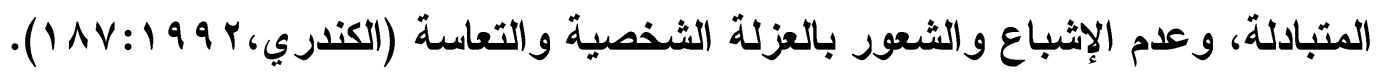

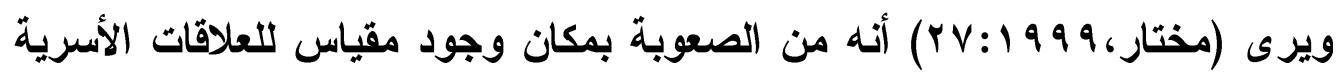

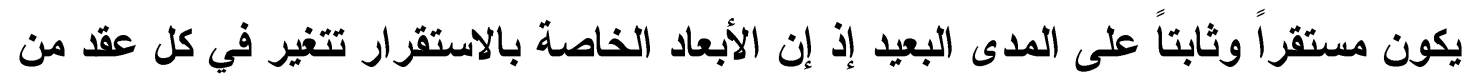
الزمان، وقد تغيرت أبعاد الاستقرار في الثمانينات عنها في التسعينات، وقد أظهرت نتائج دراسته أن مقياس عدم الاستقرار الأسري المصمم على البيئة الكويتية يحتوي على خمسة عوامل تؤدي إلى الاضطر ابات الزواجية والرغبة في الانفصال وهي: الاحترام، والاتصال المتبادل، والمصاحبة، وتلاخل الأهل في حياة الزوجين، والمشاركة في الأدوار بين الزوجين.

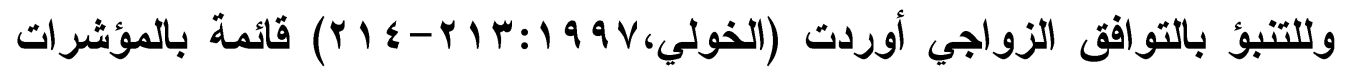

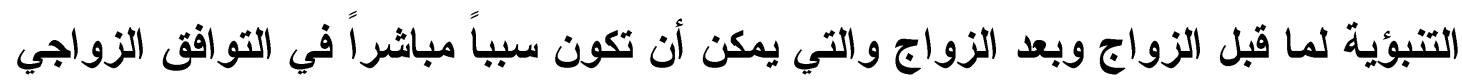

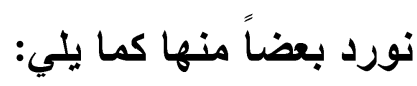
أولا: مؤشرات قبل الزواج وتثمل على: بلى التعارف، السن، الارتباط بالو الدين والصراع معهم، المواظبة على الصلاة، المستوى التعليمي. ثانياً: مؤثرات ما بعد الزواج وتثثمل على: وجود رغبة في الإججاب، عدم وجود صراع حول الأنشة والمستوى الاقتصادي الجيد، وجود وظيفة منتظمة بالنسبة للزوج، وخلو الثخصية من الاضطرابات العصابية، وأن تكون العلاقة الجنسية في إطار الزواج فقط وأن تكون الرغبة موجودة لاى الطرفين. 


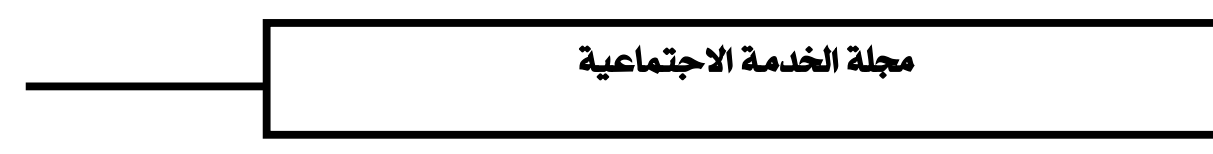

المراجع:

لسان العرب. دار الصفاء للطباعة والنشر.

ديناميات الاختيار الزواجي وعلاقته ببعض المتغيرات النفسية

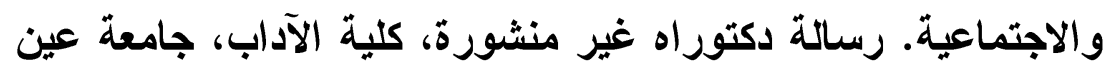
شمس: القاهرة.

مدخل إلى الصحة النفسية. الأردن: دار المسيرة للنشر والتوزيع. أبو سكينة، نادية وخضر، منال العلاقات والمشكلات الأسرية. عمان: دار الفكر. $r+11$

معجم علم الاجتماع" أول معجم شامل بكل مصطلحات علم الاجتماع

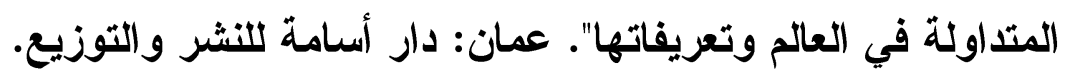

الإستقرار الزواجي دراسة في سيكولوجية الزواج. مصر: المكتبة العصرية.

التوافق الزواجي وعلاقته بأساليب المعاملة الو الاية والصحة النفسية

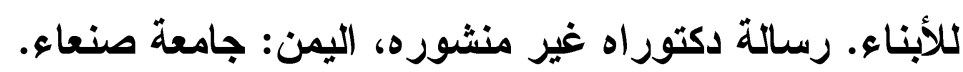

التوافق الزواجي لاى الأزواج العمانيين في ضوء بعض المتغيرات. مجلة الدراسات التربوية والنفسية، جامعة السلطان قابوس، المجلد r، العدد ا، عمان.

التوافق الزواجي وعلاقته بالعنف ضد الزوجة. رسالة ماجستير غير منشوره، الرياض: جامعة الملك سعود.

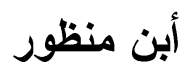

\section{$199 V$}

أبو العينين، عطيات

$199 V$

أبو حويج، الصدفي

$$
\text { r... }
$$




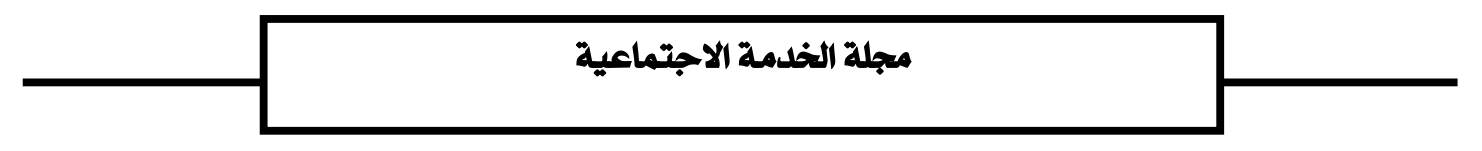

نظرة في علم الاجتماع الأسري ، الرياض: مكتبة الثقري.

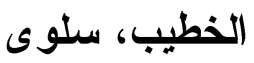

$$
r \cdot r
$$

الزواج والعلاقات الأسرية. الإسكندرية: دار المعرفة الجامعية.

الخولي، سناء

$$
199 \vee
$$

مبادئ الصحة النفسية. عمان: وائل للنشر والتوزيع.

الاهري، صالح

$$
\text { r... }
$$

أساسيات الإرشاد الزواجي والأسري. عمان: دار صفاء للنشر.

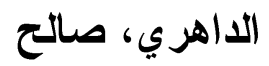

$$
r \ldots 1
$$

سيكولوجية الأسرة والو الاية. الكويت: ذات السلاسل.

التوافق بين الزوجين. مصر : دار العلم والإيمان للنشر والتوزيع.

التواقق الزواجي واستقرار الأسرة من منظور إسلامي، نفسي، اجتماعي. القاهرة: عالم الكتب.

التوافق الزواجي وعلاقته بأساليب المعاملة الزوجية وبعض سمات

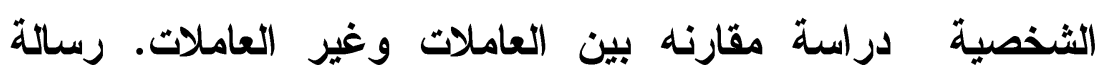
دكتوراه غير منشورة، الرياض: كلية التربية للبنات.

التوافق الزواجي في المجتمع السعودي. المملكة العربية السعودية:

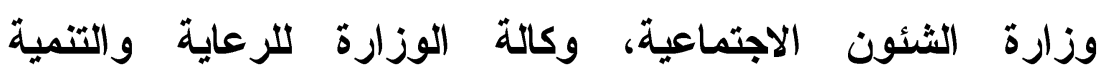
الاجتماعية، المركز الوطني للاراسات والتطوير الاجتماعي. وكاعي. مثلث التو افق الزواجي. الكويت: دار اقرأ للنشر والتوزيع.

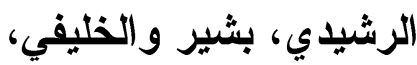

إبر اهيم

$199 V$

ز ت عتر ، وفاء

$r+1 r$

سليمان، سناء محمد

r...

الثمسان، منيرة عبدالله

$$
\text { r... }
$$

الصغير، صالح

$\rightarrow$ D

العيسى، وداد

$r \cdot q$ 


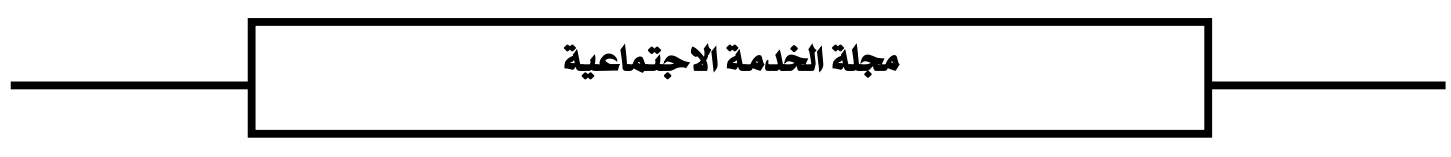

العيسوي، عبدالرحمن علم النفس الأسري "المشكلات و البرامج الإرشادية". الأردن: دار أسامة للنشر والتوزيع.

الضغوط النفسية وعلاقتها بالتوافق الزواجي وبعض المتفيرات

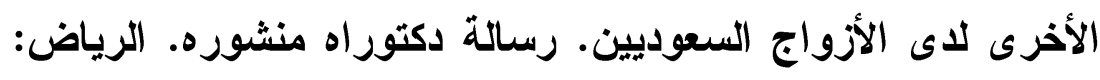

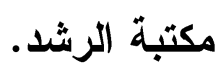

$$
\text { r.. } \varepsilon
$$

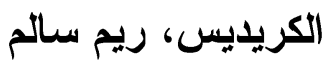

$r+11$

علم النفس الأسري. الكويت: مكتبة الفلاح. (الكندري، أحمد مبارك

1994

بناء مقياس عدم الاستقرار الأسري في المجتمع الكويتي. المجلة

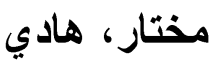

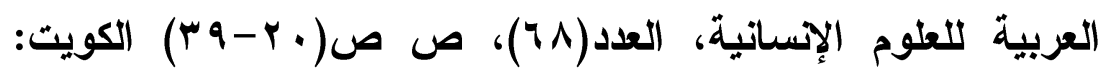
جامعة الكويت.

الأسرة و العلاج الأسري. القاهرة: دار السحاب. مؤمن، داليا محمد r... 